\title{
THE IMPROVEMENT OF THE PRECISION OF THE ARCHIMEDEAN SPIRAL TOOTHLINE GEAR CUTTING MILL
}

\author{
Hunor András GYÉRESI, ${ }^{1}$ Luciana CRISTEA, ${ }^{2}$ Márton MÁTÉ ${ }^{3}$ \\ ${ }^{1}$ Transilvania University of Brasov, Doctoral School, Brasov, Romania, hunor.gyeresi@unitbv.ro \\ ${ }^{2}$ Transilvania University of Brasov, Faculty of Product Design and Environment, Brasov, Romania, \\ lcristea@unitbv.ro \\ ${ }^{3}$ Sapientia Hungarian University of Transylvania, Faculty of Technical and Human Sciences, Department of \\ Mechanical Engineering, Târgu Mureș, Romania, mmate@ms.sapientia.ro
}

\begin{abstract}
The precision of gears has a major influence on the quality of the transmission. If the gear cannot be finished by grinding, the precision of the generating tool becomes essential. Archimedean spiral toothline cylindrical gears are obtained by reciprocate meshing using a milling cutter built up by individual cutters, organized in groups. The profiles of edges must be realized with a minimal profile error. In order to ensure the quality and the precision of the meshed tooth surface, and also the profile constancy after re-sharpening, relief faces must be realized by a grinding relieving operation. A secondary effect of the kinematics of relieving end the spatial extent of the grinding wheel a post undercut results and this produces an inevitable profile error. The present paper discusses a possible grinding wheel setting that produces a maximum theoretical profile error under $1 \mu \mathrm{m}$ along the whole re-sharpening reserve of the cutter. The proposed setting can be realized on a classical relieving lathe.
\end{abstract}

Keywords: gear cutting, milling head, relieving, profile error.

\section{The constructive principle of the milling head}

An Archimedean spiral toothline gear pair is realizable by meshing with a generating surface whose generatrix equals the classical rack profile while its direction line is an Archimedean spiral $[1,2]$. Thus, the coupling tooth flanks are builtup - with respect to Olivier's first theorem- with the use of a common meshing surface [3]. As an advantageous consequence, meshing can be performed by both gears with the same milling head. The virtual meshing rack appears with the rotation of the milling head, due to the spiral-effect. The virtual rack executes a radial motion. The kinematic scheme is shown in Figure 1. The rack has a traditional $\alpha_{0}=20^{\circ}$ profile angle. The milling head consists of $Z_{s}$ equiangular disposed cutter groups, each of them containing $Z_{k}$ b inserts. The inserts of a given group work in the same tooth gap, while the consecutive groups machine consecutive tooth gaps.

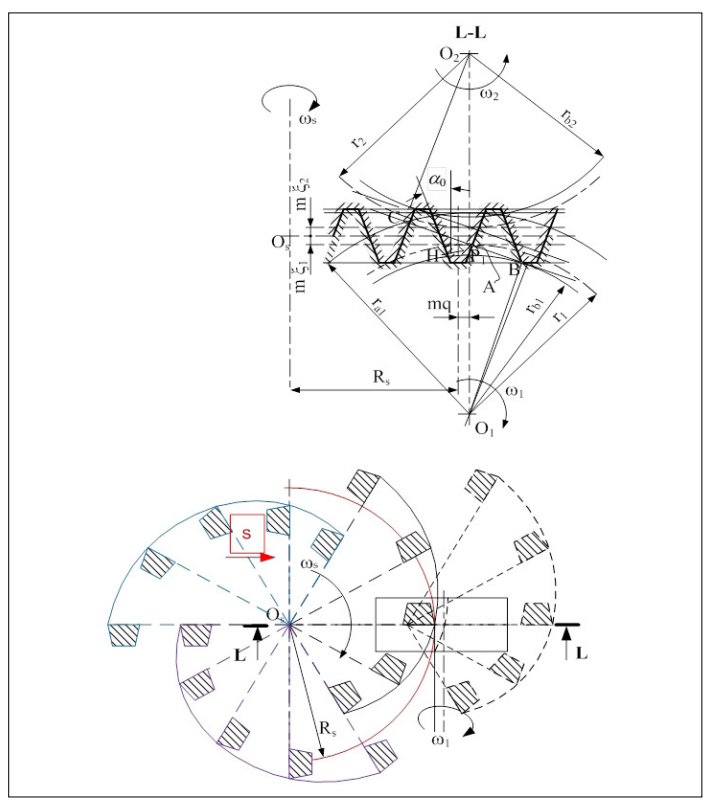

Figure 1. The appearance of the virtual rack. [4] 
Due to the special relative motion, the functional rake- and relief angles of each insert present a continuous variation. Due to this, it is necessary to compute the constructive geometry in correspondence with the kinematical peculiarities of the cutting edge's relative motion $[5,6]$.

\section{The mathematical modelling of re- lieving}

\subsection{The purpose of the model}

The model comes to describe the relative motion of the grinding wheel's surface to the cutting insert. As a result, there is a dependence between the constructive relief angle values and the setting parameters. The equations of the relief surface result also. Starting from these, the equations of the new cutting edge can be easily computed by the displacement of the rake face, due to the resharpening. This way, the occurring profile error and the variance of the relief angle can also be computed.

The model is general due to the fact it is suitable for both the concave and the convex flank machining inserts.

\subsection{Annotation}

The model uses the following annotations:

$m_{n}$ - normal module, [mm];

$\alpha_{0}$ - normal rack angle, the cutting insert profile angle, $\left[^{\circ}\right.$ ];

$u$ - cutter edge parameter, [mm];

$u_{k}$ - generatrix parameter of the grinding wheel, [mm];

$\xi$ - angular parameter of the grinding wheel, $\left[^{\circ}\right]$;

$\varphi$ - rotation of the milling head, $\left[^{\circ}\right]$;

$R_{s}$ - reference radius of the milling head, [mm];

$R_{k}$ - reference radius of the grinding wheel, [mm];

$R_{u k}$ - grinding wheel radius value corresponding to the generatrix parameter's $u_{k}$ value, [mm];

$\psi$ - half-cone angle of the grinding wheel, [ ${ }^{\circ}$ ];

$\alpha_{k n s t r}-$ constructive relief angle, $\left[^{\circ}\right]$;

$\lambda$ - relieving spiral parameter, [mm/rad].

The position of the grinding wheel related to the machined insert is shown on Figure 2. The frames shown here have the following sense:

$X_{s} Y_{s} Z_{s} \quad$ - the cutter head's frame;

$X_{k s} Y_{k s} Z_{k s}$ - the grinding wheel's frame;

$X_{0} Y_{0} Z_{0} \equiv X_{s} Y_{s} Z_{s}$ - the standing frame, the cutter head's frame coincides with at the start of the motion;

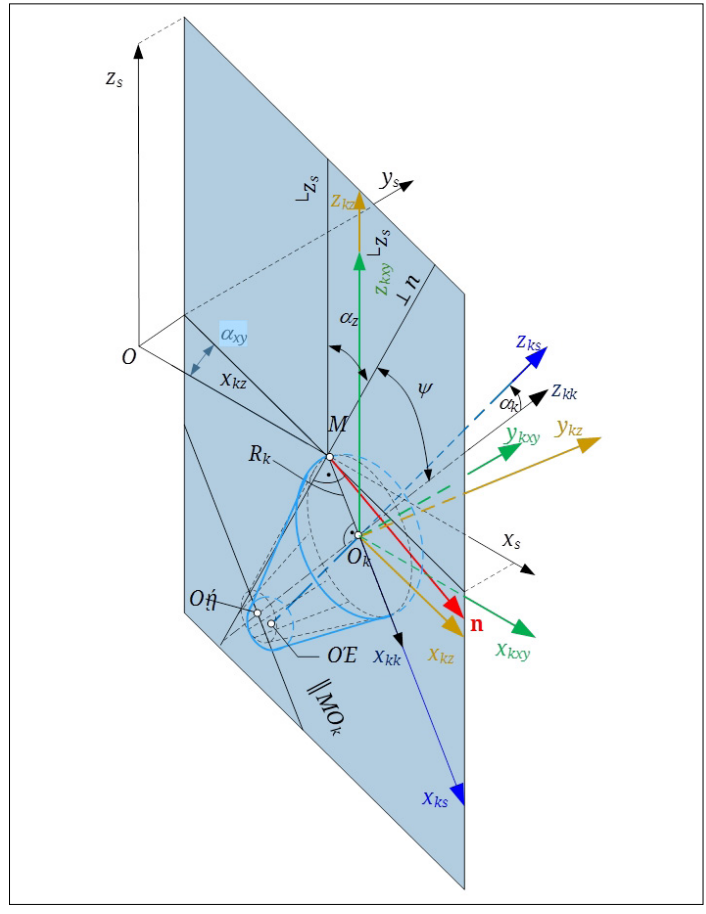

Figure 2. The frames defining the relative position of the grinding wheel and the workpiece.

$X_{k k} Y_{k k} Z_{k k}$ - the final, tilted position marking frame of the grinding wheel;

$X_{k z} Y_{k z} Z_{k z}--$ auxiliary frame, whose (zy) plane contains the direction line of the normal vector of the relief face in an arbitrary edge-point $M$;

$X_{k x y} Y_{k x y} Z_{k x y}$ - the twisted auxiliary frame (axes are parallel to their corresponding axes of $\left.X_{s} Y_{s} Z_{s}\right)$.

\subsection{The parametric equations of the relief face}

The edges of the inserts are located in the axial plane of the cutter head. Any insert can be rotated about axis $Z_{1}$ till the edge fails on the plane $X_{1} Z_{1}$. Here it must be noted that any insert is positioned at the same distance to the axis of rotation, during the relieving operation, although they occupy different positions in the cutter head. Based on the kinematics of the relieving operation [7, 8] the equations of the relief faces are as follows:

$$
\left\{\begin{array}{l}
X_{1}(u, \varphi)=\left(R_{s}+j\left(\frac{\pi m_{n}}{4}+u \operatorname{tg} \alpha_{0}\right)+\lambda \varphi\right) \cos \varphi \\
Y_{1}(u, \varphi)=\left(R_{s}+j\left(\frac{\pi m_{n}}{4}+u \operatorname{tg} \alpha_{0}\right)+\lambda \varphi\right) \sin \varphi \\
Z_{1}(u, \varphi)=u, j \in\{-1 ; 1\}
\end{array}\right.
$$


The normal vector expression in an arbitrary point of the relief face is

$$
\boldsymbol{n}(u, \varphi)=\left(\begin{array}{c}
-\lambda \sin \varphi-X_{1}(u, \varphi) \\
-\lambda \cos \varphi+Y_{1}(u, \varphi) \\
j \operatorname{tg} \alpha_{0}\left(R_{s}+j\left(\frac{\pi m_{n}}{4}+\lambda \varphi\right)\right)
\end{array}\right)
$$

\section{The geometric model of the relieving operation}

Let us suppose that the relieving operation is intended to be realized on a classical relieving lathe. The insert subjects to be relieved are positioned in equipment that confers an orientation of the inserts identical with that from the cutter head. To achieve the required orientation and setting of the grinding wheel, the grinding unit will be mounted on a support, which allows the necessary independent tilting and twisting.

Let us define the nominal diameter of the grinding wheel at the half of the tooth height, thus $R_{k}$ value of the radius corresponds to the zero value of $u_{k}$ parameter.

Let us select the point $M$ of the relief face, located on the edge, having the parametric coordinates $u=0 ; \varphi=0$. This is the midpoint of the errorless straight edge segment - also considered the reference point.

Let us take the normal vector $\mathbf{n}$ of the relief face $\Sigma_{\alpha}$ in the assigned point $\mathrm{M}$ then consider a plane containing it and parallel to the axis $O z_{s}$ This plane closes the angle $\alpha_{x y}$ with the coordinate plane $\left(x_{s} z_{s}\right)$ (the index $x y$ points the plane where the angle appears).

The axes of frame $O_{k} x_{k x y} y_{k x z} z_{k x y}$ are parallel to the axis of the fixed frame and also the equipment frame in the start position, but they are rotated about axis $z$ - by $180^{\circ}$.

Frame $O_{k} x_{k z} y_{k z} z_{k z}$ results as the effect of rotation of frame $O_{k} x_{k x y} y_{k x z} z_{k x y}$ about axis $O_{k} z_{k x y}$ with $-\alpha_{x y}$ where the minus sign denotes the clockwise sense.

In the following, the positioning of the grinding wheel's axis in the plane $\left(O_{k} x_{k z} z_{k z}\right)$ will be analysed, as shown in Figure 3.

The grinding wheel's surface is a cone.

The cone is set in such a manner that its generatrix coincides, in point $M$ with the perpendicular of the normal vector $\mathbf{n}$ of the relief face $\left(\Sigma_{\alpha}\right)$ Both are included in the tangent plane of the relief face. In this case the angle between axes $x_{k k}$ and $x_{k z}$ equals the algebraic sum of the cone half angle $\psi$ and the angle $\alpha_{z}$ between the normal vector and the plane $\left(x_{s} y_{s}\right)$ :

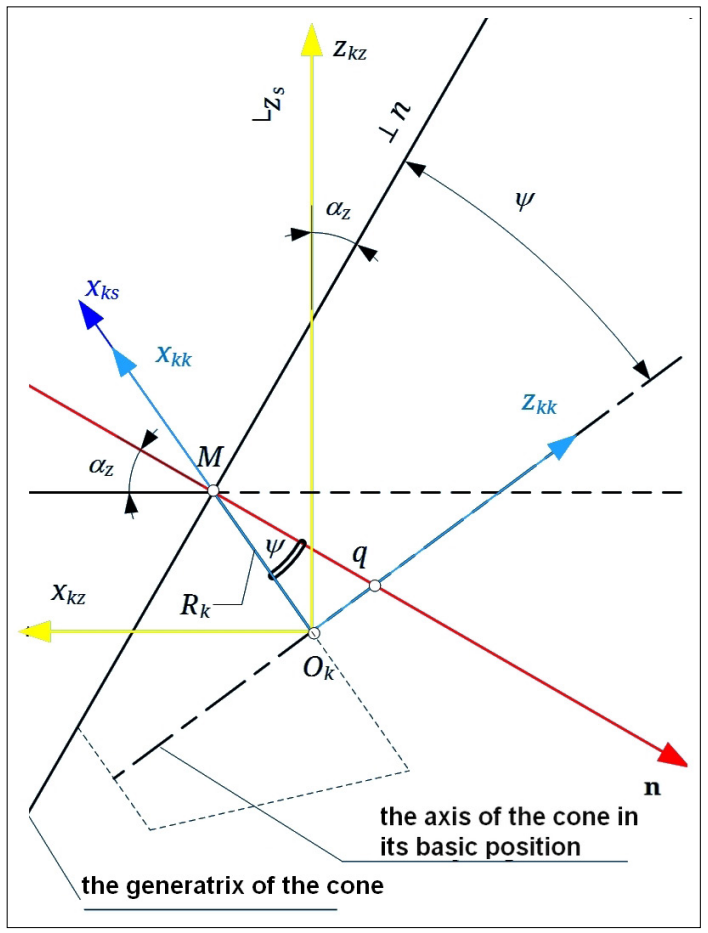

Figure 3. The initial position of the grinding wheel.

$$
\alpha_{z}^{*}=\alpha_{z}+\psi
$$

In the situation shown in Figure 3, the tip of the cone falls in the direction of the edge tip, $\psi>0$, otherwise $\psi<0$. Axes $y_{k z}$ and $y_{k k}$ are coincident and implicitly, perpendicular on the blue, normal vector containing plane, shown in Figure 3. Thus, the result is that frame $O_{k} x_{k k} y_{k k} z_{k k}$ is, by definition, the frame of the grinding wheel, in machining position. It results from the effect of rotation of the grinding wheel's frame, starting from the basic position $O_{k} x_{k z} y_{k z} z_{k z}$ about axis $y_{k z}$ by angle $-\alpha_{z}^{*}$.

The frame $O_{k} x_{k s} y_{k s} z_{k s}$ is, by definition, the frame of the grinding wheel, in machining position. It results from the effect of rotation of the grinding wheel's frame, starting from the basic position $O_{k} x_{k k} y_{k k} z_{k k}$ about axis $x_{k k} \equiv x_{k s}$ called hereafter tilting. The reason for introducing this tilting is due to the in the fact that only the normal vector in reference point $M$ crosses the axis of the cone, while all other edge-points, are avoiding it. The coincidence of normal vector support lines in the common point of two surfaces is the basic condition of the surface mating. Let us denote the tilt angle by $\alpha_{k}$. Figure 4 . shows that, normal vectors of the relief face, defined in the edge tip respectively in the edge root, present opposite 


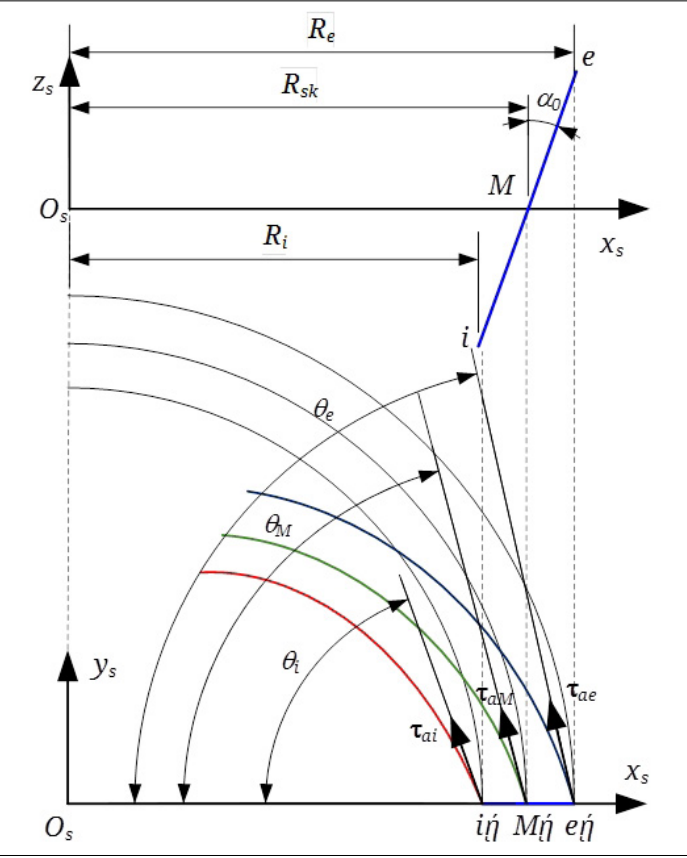

Figure 4. The change of the direction of the normal vector in different edge-points-projection.

inclinations from the normal vector defined in $M$ That geometric peculiarity justifies the necessity of tilting: applying it, e.g. the rotation about axis $x_{k k}$ the mating condition will persist in the reference point, while in the extremities, they approach in the the best way the grinding wheel's axis. This way, the reference point possesses a common normal line, while the normal lines in the other points pass as near as possible next to the grinding wheel's axis.

Based on Figure 2. the vectorial parametric surface equations of the grinding wheel are as follows:

$$
\begin{gathered}
r_{k s}\left(u_{k}, \xi\right)=\left(\begin{array}{c}
-R_{u k} \cos \xi \\
-R_{u k} \sin \xi \\
u_{k}
\end{array}\right) \\
R_{u k}=R_{k}-u_{k} \operatorname{tg} \psi
\end{gathered}
$$

In parametric equation (4) $R_{k}$ denotes the nominal middle radius value of the grinding wheel, $\psi$ the half angle of the cone, while, $u_{k}$ and $\xi$ are the independent parameters of the conical surface, and the height- and the angular parameter. The length of the edge segment equals the length of the generatrix, and is a function of $u$.

Considering that the useful length of the edge coincides with that of the cone generatrix, the parameters $u_{k}$ and $u$ are bound by the following expression:

$$
\frac{u_{k}}{\cos \psi}=\frac{u}{\cos \alpha_{0}}
$$

Using coordinate expressions (2) of the normal vector, the slope of this, relative to the plane $x_{k z}$ $z_{k z}$ can be computed as:

$$
\alpha_{x y}=-\operatorname{arctg} \frac{\lambda}{R_{s}+\frac{\pi m_{n}}{4}}
$$

Angle $\alpha_{z}$ from expression (3) can be deduced from the parametric coordinates (2) by particularizing them to $\varphi=0$ value:

$$
\alpha_{z}=-\operatorname{arctg}\left(\operatorname{tg} \alpha_{0} \cos \alpha_{x y}\right)
$$

As an effect of the tilt, the axis of the grinding wheel leaves the position $z_{k k}$ and overlaps $z_{k z}$ signifying the rotation of frame $x_{k k} y_{k k} z_{k k}$ about axis $x_{k k} \equiv x_{k s}$

The value of the rotation angle $\alpha_{k}$ is computed admitting that the normal vector directions in the edge tip and edge root point should be situated as near as possible to the axis of the relieving grinding wheel.

Let us define the next trigonometric function:

$$
\operatorname{tg} \theta(u)=\frac{\lambda}{R_{s}+\frac{\pi m_{n}}{4}+u \operatorname{tg} \alpha_{0}}
$$

Due to their excessive extent, we consider the justifying calculus can be omitted here. The value of the tilt angle $\alpha_{k}$ with respect to (8), becomes

$$
\begin{aligned}
\operatorname{tg} \alpha_{k}= & \frac{R_{k}\left(\operatorname{tg} \theta\left(m_{n}\right)-\operatorname{tg} \theta\left(-m_{n}\right)\right) \cos \alpha_{z}}{2 m_{n}}- \\
& -\operatorname{tg} \alpha_{0} \sin \alpha_{x y} \cos \alpha_{z}
\end{aligned}
$$

The transformation matrix that links the proper $\left(x_{k s} y_{k s} z_{k s}\right)$ frame of the grinding wheel and the auxiliary frame $\left(x_{k x y} y_{k x y} z_{x k y}\right)$ can be obtained by the chaining of three elementary rotations as follows:

$$
\boldsymbol{M}_{(k x y, k s)}=\boldsymbol{M}_{(k x y, k z)} \boldsymbol{M}_{(k z, k k)} \boldsymbol{M}_{(k k, k s)}
$$

Elements of matrix (10) are denoted by $m_{i j}, i, j \in \overline{1,3}$.

If using a classical relieving lathe, rotation angles given by (3), (6), (7), (9), which are necessary to define the positioning of the grinding wheel defined given by (10), cannot be varied, thus they will stay at constant values hereafter.

In the next the linearized model we will present the case where the normal-unit vector will be used. This, using expressions (1) and (2) can be put in the following form: 


$$
\left\{\begin{array}{c}
n_{x}(\varphi)=R_{s}+\frac{m_{n} \pi}{4}+\lambda \varphi \\
n_{y}(\varphi)=-\lambda \\
n_{z}(\varphi)=-n_{x}(\varphi) \operatorname{tg} \alpha_{0} \\
l(\varphi)=\sqrt{\left(R_{s}+\frac{m_{n} \pi}{4}+\lambda \varphi\right)^{2}\left(1+\operatorname{tg}^{2} \alpha_{0}\right)+\lambda^{2}}
\end{array}\right.
$$

From here results:

$$
e_{k}(\varphi)=\frac{n_{k}(\varphi)}{l(\varphi)}, k \in\{x ; y ; z\}
$$

\section{The equations of meshing surface}

During the relieving operation the grinding wheel executes a radial linear motion while the holder equipment rotates about the lathe's axis. This is geometrically primed as the rotation and radial approaching of frame $x_{k x y} y_{k x y} z_{k x y}$ relative to the frame $x_{s} y_{s} z_{s}$ (Figure 2).

There exists a linear dependence between the motions mentioned above.

Let us point with vector $\boldsymbol{r}_{0 k}=\left(\begin{array}{lll}x_{0 k} & y_{0 k} & z_{0 k}\end{array}\right)^{T}$ the center of the grinding wheel when the rotation angle is set to zero (in the initial phase corresponding to $\varphi=0$ ) and define the relative linear motion unit vector by $\boldsymbol{\delta}=\left(\begin{array}{lll}\delta_{x} & \delta_{y} & \delta_{z}\end{array}\right)^{T}$. Using this, the trajectory of the center point of the grinding wheel, for an angular interval $\varphi \in\left[\varphi_{0} ; \varphi_{v}\right]$, marking the real amount of the rotation, can be written as:

$$
\boldsymbol{r}_{0}(\varphi)=\boldsymbol{r}_{0 k}+\left(\varphi-\varphi_{0}\right) \boldsymbol{\delta}
$$

Using the parallelism of axes of frames $x_{k x y} y_{k x y} z_{k x y}$ and $x_{0} y z_{0}$ the equations of the grinding wheel's surface related to the frame of the machine body can be written as:

$$
\boldsymbol{r}_{0 p}\left(\varphi, u_{k}, \xi\right)=\boldsymbol{r}_{0 k}+\boldsymbol{r}_{k x y}\left(u_{k}, \xi\right)+\left(\varphi-\varphi_{0}\right) \boldsymbol{\delta}
$$

The meshed surface family, generated by the grinding wheel during the relative motion, in the frame of the insert becomes:

$$
\boldsymbol{r}_{s}\left(\varphi, u_{k}, \xi\right)=\boldsymbol{M}_{s, 0}\left(\boldsymbol{r}_{0}+\boldsymbol{r}_{k x y}\left(u_{k}, \xi\right)+\left(\varphi-\varphi_{0}\right) \boldsymbol{\delta}\right)
$$

where:

$$
\begin{gathered}
\boldsymbol{M}_{s, 0}=\left(\begin{array}{ccc}
\cos \varphi & -\sin \varphi & 0 \\
\sin \varphi & \cos \varphi & 0 \\
0 & 0 & 1
\end{array}\right) \\
\boldsymbol{r}_{k x y}\left(u_{k}, \xi\right)=\boldsymbol{M}_{(k x y, k s)} \boldsymbol{r}_{k s}\left(u_{k}, \xi\right)
\end{gathered}
$$

In correspondence with Figure 2, the initial and the final position of the grinding wheel's center point, related to the fixed frame, can be written as:

$$
r_{0}^{\langle q\rangle}=\left(\begin{array}{c}
R_{s}+\frac{m_{n} \pi}{4}+\lambda \varphi_{q}+e_{x}\left(\varphi_{q}\right) R_{k x y}^{*} \\
e_{y}\left(\varphi_{q}\right) R_{k x y}^{*} \\
e_{z}\left(\varphi_{q}\right) R_{k x y}^{*}+\Delta_{z}\left(\varphi_{q}\right)
\end{array}\right), q \in\{0 ; v\}
$$

where:

$$
\begin{aligned}
R_{k x y}^{*}= & R_{k} \frac{\cos \left(\alpha_{z 0}+\psi\right)}{\cos \alpha_{z 0}} \\
\Delta_{z}(\varphi)= & R_{k}\left[\operatorname{tg}\left(\alpha_{z}(\varphi)+\psi\right)-\operatorname{tg} \alpha_{z}(\varphi)\right] . \\
& \cdot \cos \left(\alpha_{z}(\varphi)+\psi\right)
\end{aligned}
$$

Using this, and knowing that the relieving tool holder's motion possibilities on the classic relieving machine are only linear, the direction of this results as

$$
\boldsymbol{\delta}=\frac{\boldsymbol{r}_{0}\left(\varphi_{v}\right)-\boldsymbol{r}_{0}\left(\varphi_{0}\right)}{\varphi_{v}-\varphi_{0}}
$$

The meshing surface's parametric coordinates are obtained from vector (15), by the introduction of the dependence between the surface family parameters written as $\xi=\xi\left(u_{k}, \varphi\right)$ Because of the very laborious calculus this is omitted, and the mentioned relation will be given by the following expression suit:

$$
\begin{aligned}
& D_{x}=r_{0 k x}+m_{13} u_{k}+\left(\varphi-\varphi_{0}\right) \delta_{x}+\delta_{y} \\
& D_{y}=-r_{0 k y}-m_{23} u_{k}-\left(\varphi-\varphi_{0}\right) \delta_{y}+\delta_{x} \\
& A=R_{u k} \operatorname{tg} \psi \cos \alpha_{z}^{*} \sin \alpha_{k}-\delta_{z} \sin \alpha_{z}^{*}- \\
& \quad-\left(D_{x} \sin \alpha_{x y}+D_{y} \cos \alpha_{x y}\right) \cos \alpha_{z}^{*} \\
& B=-R_{u k} \operatorname{tg} \psi \sin \alpha_{z}^{*}-\delta_{z} \cos \alpha_{z}^{*} \sin \alpha_{k}- \\
& -D_{x}\left(\cos \alpha_{x y} \cos \alpha_{k}-\sin \alpha_{x y} \sin \alpha_{k} \sin \alpha_{z}^{*}\right) \\
& +D_{y}\left(\sin \alpha_{x y} \cos \alpha_{k}+\cos \alpha_{x y} \sin \alpha_{k} \sin \alpha_{z}^{*}\right) \\
& C= \\
& \quad \operatorname{tg} \psi\left[-D_{x}\left(\cos \alpha_{x y} \sin \alpha_{k}+\right.\right. \\
& \left.\quad+\sin \alpha_{x y} \cos \alpha_{k} \sin \alpha_{z}^{*}\right)+ \\
& \quad+D_{y}\left(\sin \alpha_{x y} \sin \alpha_{k}-\cos \alpha_{x y} \cos \alpha_{k} \sin \alpha_{z}^{*}\right)+ \\
& \left.\quad+\delta_{z} \cos \alpha_{z}^{*} \cos \alpha_{k}\right]
\end{aligned}
$$

Any of expressions (22a...e) are dependent on $u_{k}$ and $\varphi$. Thus, the meshing condition results under the form:

$$
\operatorname{tg} \xi=\frac{A B \pm C \sqrt{A^{2}+B^{2}-C^{2}}}{C^{2}-B^{2}}
$$

As shown from expression (21), the direction of the relative motion of the grinding wheel to the machine body is defined on all three axes; but the construction of the relieving lathe allows only two of these. That fact necessitates a correction. 
The motion will be transferred in a plane that contains the axis of rotation of the lathe and it is parallel with the $\delta$ direction. The angle comprised between this plane and plane $(x y)$ is:

$$
\operatorname{tg} \varepsilon=\frac{\delta_{y}}{\delta_{x}}
$$

With this correction, the equations of the meshed surface become:

$$
\boldsymbol{r}_{\varepsilon}=\boldsymbol{M}_{\varepsilon} \boldsymbol{M}_{s, 0}\left(\boldsymbol{r}_{0}+\boldsymbol{r}_{k x y}\left(u_{k}, \xi\right)+\left(\varphi-\varphi_{0}\right) \boldsymbol{\delta}\right)
$$

$M_{\varepsilon} M_{s, 0}=$

$=\left(\begin{array}{ccc}\cos \varepsilon & -\sin \varepsilon & 0 \\ \sin \varepsilon & \cos \varepsilon & 0 \\ 0 & 0 & 1\end{array}\right)\left(\begin{array}{ccc}\cos \varphi & -\sin \varphi & 0 \\ \sin \varphi & \cos \varphi & 0 \\ 0 & 0 & 1\end{array}\right)$

$=\left(\begin{array}{ccc}\cos \varphi & -\sin \varphi & 0 \\ \sin \varphi & \cos \varphi & 0 \\ 0 & 0 & 1\end{array}\right)\left(\begin{array}{ccc}\cos \varepsilon & -\sin \varepsilon & 0 \\ \sin \varepsilon & \cos \varepsilon & 0 \\ 0 & 0 & 1\end{array}\right)$

After the development of (26) results:

$$
\begin{aligned}
& \boldsymbol{r}_{\varepsilon}=\boldsymbol{M}_{s, 0}\left(\boldsymbol{r}_{0 \varepsilon}+\boldsymbol{r}_{k x y \varepsilon}\left(u_{k}, \xi\right)+\left(\varphi-\varphi_{0}\right) \boldsymbol{\delta}_{\varepsilon}\right) \\
& \boldsymbol{r}_{0 \varepsilon}=\boldsymbol{M}_{\varepsilon} \boldsymbol{r}_{0} \\
& \boldsymbol{r}_{k x y \varepsilon}\left(u_{k}, \xi\right)=\boldsymbol{M}_{\varepsilon} \boldsymbol{r}_{k x y}\left(u_{k}, \xi\right) \\
& \boldsymbol{\delta}_{\varepsilon}=\boldsymbol{M}_{\varepsilon} \boldsymbol{\delta}=\left(\begin{array}{c}
\delta_{x \varepsilon} \\
0 \\
\delta_{z}
\end{array}\right)
\end{aligned}
$$

\section{Numerical investigation}

By proofing the model, the following initial values were used:

$$
\begin{array}{ll}
\alpha_{0}=20^{\circ} & - \text { standard profile angle } \\
m_{n}=5 \mathrm{~mm} & \text { - normal module } \\
R_{s}=80 \mathrm{~mm} & \text { - radius of insert holder } \\
R_{k}=80 \mathrm{~mm} & \begin{array}{l}
\text { - middle radius of the grinding } \\
\text { wheel }
\end{array} \\
\psi=-1^{\circ} & \text { - half cone angle of the grinding } \\
& \text { wheel } \\
\alpha_{k n s t r}=-4^{\circ} & \text { - prescribed constructive relief } \\
\phi_{0}=0^{\circ} & \text { angle } \\
\phi_{v}=10^{\circ} & \text { - lower resharpening limit }
\end{array}
$$

Figure 5. shows the grinding wheel' surface in the initial, the middle and the final position of the relieving motion, contacting the meshing relieving surface. Red lines represent the edges obtained after applying the resharpening. These were computed using numerical methods.

Due to the particularity of the relieved surfaces, resharpening causes the radial shift of the cutting edge. Here a radial correction is necessary after each conditioning. It consists in the radial shift-

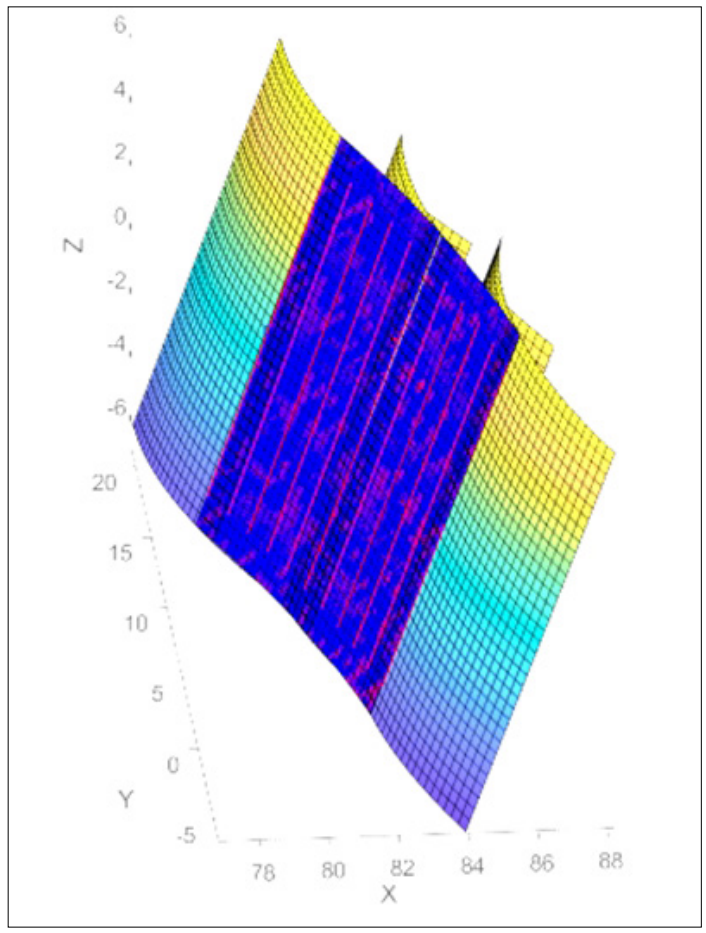

Figure 5. The relieving face and the grinding wheel's surface - in different moments of the machining.

ing of the insert, till the characteristic point of the new edge fail on the theoretical point $M$ of the initial edge. All errors were computed considering the correction performed.

The constructive relief angle increases with the height of the considered point on the edge. Due to the resharpening, a variation of the relief angles also occur, on both these 's magnitude is of sexadecimal minutes.

The magnitude of the computed theoretical profile error is also negligible until it is of order of tenths of micron.

\section{Conclusion}

With the implementation of the proposed mathematical model, a cost-efficient relieving operation of the inserts can be achieved by use of a classical relieving lathe.

The model is suitable for both the inner and outer cutting inserts.

The relief angles and the re-sharpening reserve can be defined in comfortable large intervals. In spite of this, the variation of the relief angle and the theoretical profile error after the resharpening are of negligible magnitudes. 


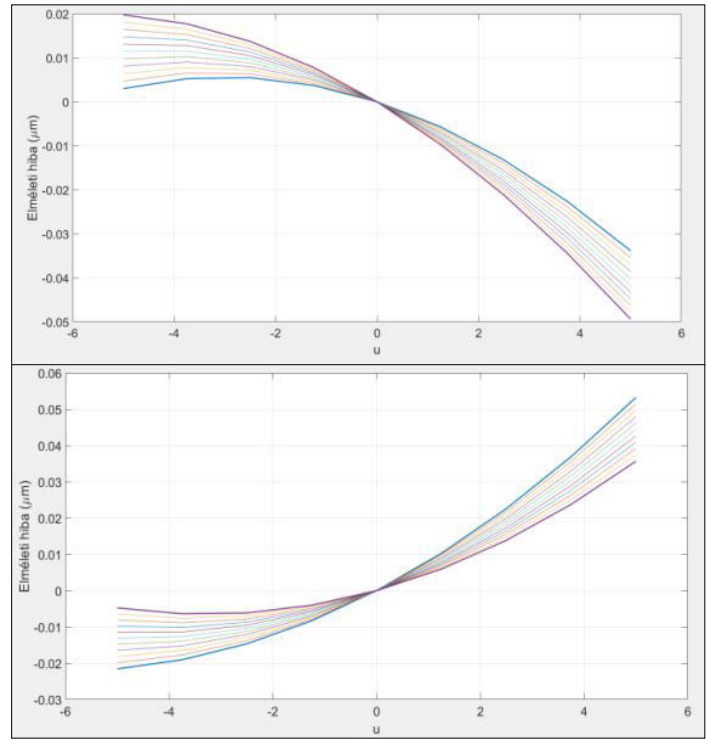

Figure 6. The variation of the theoretical profile error in relation to the height parameter ' $u$ ' and the number of resharpening (upper: interior edge; under: exterior edge).

\section{References}

[1] Máté M.: Spirálfogazatú hengeres kerekek geometriája és gyártáselmélete. Kutatási beszámoló. MTA Domus Kuratórium, 2011. évi A2011061. számú pályázat, Budapest, 2011.1-18.

[2] Máté M.: Tangenciális lefejtéssel megvalósított Arkhimédész-féle spirál vezérgörbéjü fogazatok lefejtésének tanulmányozása. Kutatási beszámoló. A2-NJN-TOK-13-0009 azonosítójú, Neumann János kutatási beszámoló. 1-42.

[3] Litvin F. L.: A fogaskerék-kapcsolás elmélete. Budapest, Múszaki Könyvkiadó, 1972. 113-127.

[4] Máté M.: The micro-geometric model of the toothflanks of a cylindrical gear with archimedean spiral shaped toothline. In: $6^{\text {th }}$ International Scientific and Expert Conference TEAM 2014. 1-8.

[5] Gyéresi H. A.: A csigamarós fogaskerék-lefejtő gép kiegészitése az Arkhimédész-féle spirális fogirányvonalú fogaskerekek megmunkálásához. Államvizsga-dolgozat, Sapientia EMTE, 2016.

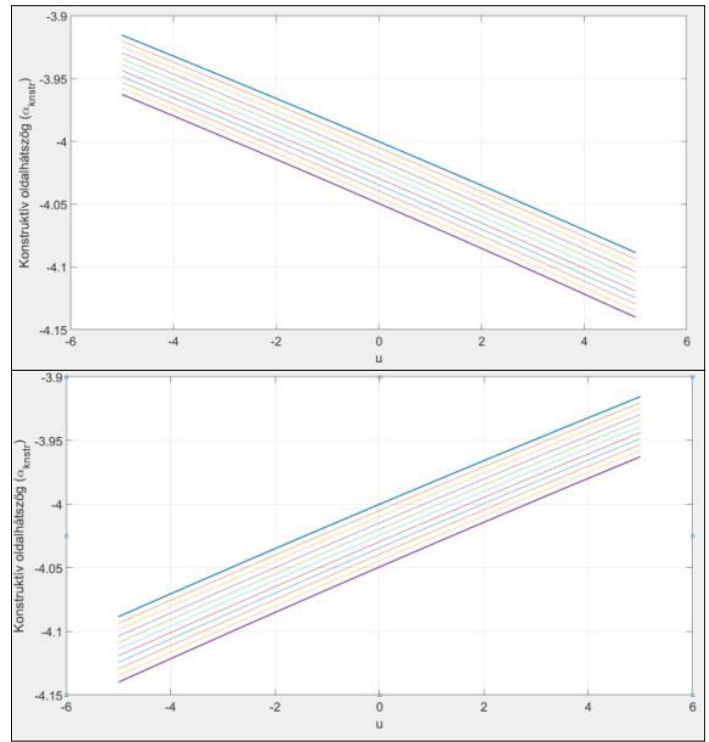

Figure 7. The variation of the constructive side relief angle in relation to the edge parameter ' $u$ ' and the number of resharpening (upper: interior edge; under: exterior edge).

[6] Máté M., Gyéresi H. A.: About the Profile Constancy by Curved Teeth Cylindrical Gear's Cutter Head. In: MACRO-2015-International Conference on Recent Achievements in Mechatronics, Automation, Computer Science and Robotics. Tîrgu-Mures, Romania, March 6-7, 2015. Conference Proceedings. ISSN, ISSN-L: 2247-0948.13-24.

https://doi.org/10.1515/macro-2015-0002

[7] Ábel J., Balajti Zs.: Szerszámél geometriai vizsgálatához szükséges feltétel, a Monge-tégla bijektív tartományának határfelülete. In: XXVII. Nemzetközi Gépészeti Konferencia, Nagyvárad, ISSN 2068-1267 OGÉT, 2019. április 25-28., 22-26. .

[8] Balajti Zs., Dudás, I.: The Monge Theorem and Its Application in Engineering Practice. In: International Journal of Advanced Manufacturing Technology, 91/1-4. (2017) 739-749.

https://doi.org/10.1007/s00170-016-9763-1 